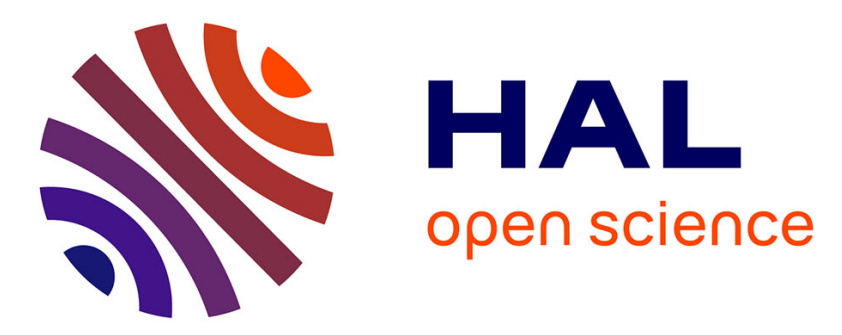

\title{
On the Use of City Bikes to Make the City Even Smarter
}

Nathalie Mitton, Hervé Rivano

\section{To cite this version:}

Nathalie Mitton, Hervé Rivano. On the Use of City Bikes to Make the City Even Smarter. SSC International SMARTCOMP Workshop on Sensors and Smart Cities, Nov 2014, Hong-Kong, China. hal-01074478

\section{HAL Id: hal-01074478 \\ https://hal.inria.fr/hal-01074478}

Submitted on 20 Nov 2014

HAL is a multi-disciplinary open access archive for the deposit and dissemination of scientific research documents, whether they are published or not. The documents may come from teaching and research institutions in France or abroad, or from public or private research centers.
L'archive ouverte pluridisciplinaire HAL, est destinée au dépôt et à la diffusion de documents scientifiques de niveau recherche, publiés ou non, émanant des établissements d'enseignement et de recherche français ou étrangers, des laboratoires publics ou privés. 


\title{
On the use of city bikes to make the city even smarter
}

\author{
Nathalie Mitton*, Hervé Rivano*† \\ *Inria, France - Email: firstname.lastname@inria.fr \\ ${ }^{\dagger}$ CITI, INSA Lyon, France
}

\begin{abstract}
These last years have witnessed the rise of the smart cities and several mechanisms to render the cities more sustainable and more energy-efficient. Among all different aspects is transportation and urban bike development. Besides the growing enthusiast provoked by bicycles and the benefit for health they bring, there still exists some reluctance in using bikes because of safety, road state, weather, etc. To counter-balance these feelings, there is a need to better understand bicycle users habits, path, road utilization rate in order to improve the bicycle path quality. In this perspective, in this paper, we propose to deploy a set of mobile sensors on bicycles to gather this different data and to exploit them to make the bike easier and make people want to ride bicycles more often. Such a network will also be useful for several entities like city authorities for road maintenance and deployment, doctors and environment authorities, etc. Based on such a framework, we propose a first basis model that help to dimension the network infrastructure and the kind of data to be real time gathered from bikes. More specifically, we present a theoretical model that computes the quantity of data a bike will be able to send along a travel and the quantity of data a base station should be able to absorb. We have based our study on real data to provide first numerical results and be able to draw some preliminary conclusions and open new research directions.
\end{abstract}

\section{INTRODUCTION}

Cities are growing steadily and urban living poses major challenges in our daily lives. As of 2007, $50 \%$ of the population of the world was living in cities. The United Nations Population Fund forecasts that by 2030 approximately $60 \%$ of the world population will live in an urban environment [11].

Among all issues that are raised by this phenomenon, we can highlight air quality, environmental crisis and transportation issues. Bicycling is an important part of the solution to many urban transportation issues since the growing increase in motor vehicle use is burdening cities with increasing problems and costs related to congestion, accidents, loss of amenity and space, noise, poor quality of life, poor urban air quality and energy consumption, having adverse effects on both the natural and built environment. Bicycle transport must be an integral part of the transportation solution for the cities of the future. It presents many economical and ecological benefits as shown by many studies [12], [13]. Also note that increasing use of bicycle has a positive side effect on health like highlighted in [2] since it helps people to make more physical activity.

These last years have witnessed a large increase in the bike utilization in big cities [6], [5], offering a winning combination with traditional urban transportations [8]. New applications arise around the bicycle to make it smarter [1]. But in spite of all, there still exists some reluctance in using bikes [10], [3]. Among the top reasons mentioned by people are the arguments that bicycle is too dangerous, distances are too long and the weather is not good enough for cycling.

To counter-balance these feelings, there is a need to better understand bicycle habits, path, utilization rate in order to improve the bicycle path quality. In this perspective, we propose to deploy a set of mobile sensors on bicycles to gather this different data and to exploit them to make the bike easier and make people want to ride bicycle more often. We believe that such a perspective is needed by authorities and cities as attested by the current action launched by the city of London [14], which would like to crowd-collect data to better plan cycling path and "creating a cycling infrastructure that takes cyclists where they actually want to go". Once sensors deployed, they can be used to sense extra kinds of physical measures. Another measure of interest is the air contamination. Equipping bikes with such a sensor and retrieving the information would allow the drawing of an accurate air pollution map and the mapping with some illness propagations. This latter point is asked by several medical centers and doctors. Yet, a great number of useful applications coud be drawn on such an infrastructure.

To this purpose, the embedded sensors should be able to opportunistically communicate through wireless with other embedded sensors (on other bikes) and some fixed infrastructure when available. Envisioned data to be collected is of three kinds:

- Self-quantitizing : tours/minutes, speed, effort, rhythm, etc. Such data could be collected by the user's smartphone and are private data. They can help the biker to better measure their physical activity.

- Community : quality of the journey, road conditions, available parking places, road utilization, pedestrian and bike density, etc. Such data are destined to cross entities like city authorities, urban bikes or rental bike operators, etc Such data has to be made anonymous 
and locally broadcast.

- Urban sensing : air quality, noise pollution, weather, etc. Such data aims to be collected to a central system for a posteriori processing and public information. It would allow further study and correlation between illness and pollution.

All together, these sets of data may drive the choice of the traveler in terms of kind of transportation, trajectory, etc) and help the authorities to anticipate some road maintenance, street lighting and securing or to draw new bike paths. Such information has also been collected in a similar approach called BikeNet [9] but in that project, there are collected and processed a posteriori and not sent along the bicycle path.

This paper is a prospective paper that aims to a proof of concept of what could be achieved and how from such data. To do so, in this paper, we present a first basis model that help to dimension the network infrastructure and the kind of data to be real time gathered from bikes. The different parameters used in our study and the different assumptions will be later exposed in a more complex manner to fit the city values and statistics. More specifically, we present a model that computes the quantity of data a bike will be able to send along a travel and the quantity of data a base station should be able to absorb. We have based the study on real data to provide first numerical results and be able to draw some preliminary conclusions.

We expect such a study to be the basis (i) to proportion a network in terms of available bandwidth, transmitting power and number of base stations, (ii) help in the determination of base stations locations (ii) help in the triggering of opportunistic multi-hop routing vs direct communication when and where needed.

The remaining of this paper is as follows. Our model and motivations are presented in Section II. Section III presents a first simple study as a proof of concept of our model and results are displayed and discussed in Section IV. Based on this, Section V discusses the different opportunities opened by these results and finally Section VI concludes the paper by highlighting future research directions.

\section{MODEL}

We assume a city in which there are some self-service share bikes as this is the case in a growing number of cities around the world. We assume the bike stations are equipped with a base station and are deployed over the city with a density $\lambda_{\text {station }}(x)$ which is a function of the position $x$ in the city. We assume that these stations are equipped with wireless base stations able to collect the data sensed and sent by the bikes within a range of $R_{i}$ where $R_{i}$ is the transmission range of base station $i$. On Figure 1(b), the roads, cycling paths and bike stations are represented. Red circles are centered on the self-service bike stations and show the coverage area of a base station located at this bike station. We assume that every bike can upload data at the rate of $\rho$.

We assume that bikes are distributed over the different roads of the city, that they move with a speed $v$ and that their density $\lambda_{\text {bike }}(x, t, w)$ varies as a function of the location $x$ in the city, the time of the day $t$ and of the weather $w$.

We are interested on the following values:

- $\chi$ amount of data a bike is able to directly send to a base station during a trip,

- $\mathcal{Q}_{t}$ quantity of data every base station should be able to absorb during time $t$.

Such values would later be used to better determinate :

- the capacities of base stations,

- the transmission range $R_{i}$ of each base station $i$,

- whether some additional base station should be added and where,

- how long a bike will have to wait to be able to upload its data to a base station. If this duration is too long with regards to the data importance or the storage capacity of the embedded sensors in the bike, the bike will have to trigger an opportunistic multi-hop routing protocol to avoid data loss.

\section{A SIMPLE STUDY}

As already mentioned, the main purpose of this paper is to set the basis of our concept and give a first simple study as a proof of concept of the kind of values to be retrieved in a Smart City by equipping the bikes of some wireless sensors. Let $X_{x}$ and $Y_{x}^{t}$ be two random variables counting the number of base stations covering a position $x$ and the number of bikes at position $x$ at time $t$, respectively. .

For this first analysis, we make the following simplifying assumptions :

- every base station has the same transmission range : $\forall i R_{i}=R$,

- the distribution of the base stations is uniform and follows a stationary Poisson Point distribution process $\Phi_{\text {station }}$ of density $\lambda_{\text {station }}(x)=\lambda_{\text {station }}$,

- the distribution of the bicycles is uniform at a time $t$ and of density $\lambda_{\text {bike }}(x, t, w)=\lambda_{\text {bike }}^{t}$,

- data can be offloaded to a base station as soon as a bike is in communication range of it,

- traffic generated by a bike located at a position covered by several base stations is, in average, equally distributed/absorbed by each of these base stations (i.e. if a bike is at a point in transmission range of base stations $\mathrm{A}$ and $\mathrm{B}$, its traffic will be distributed between $\mathrm{A}$ and $\mathrm{B}$ evenly in average). To better figure this assumption, let us consider the situation depicted on Figure III with three bikes and three base stations. Bicycle $B$ lies in the coverage area of he three base stations at once. We assume that its traffic will be distributed among the three base stations. Bike $A$ is only covered by base station 1 which will have to 


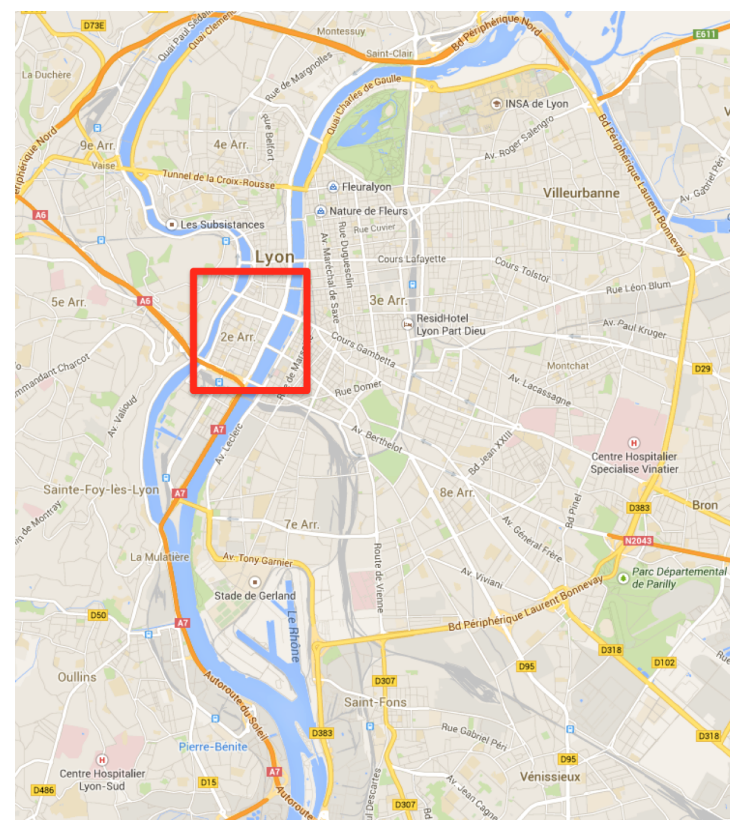

(a) City of Lyon

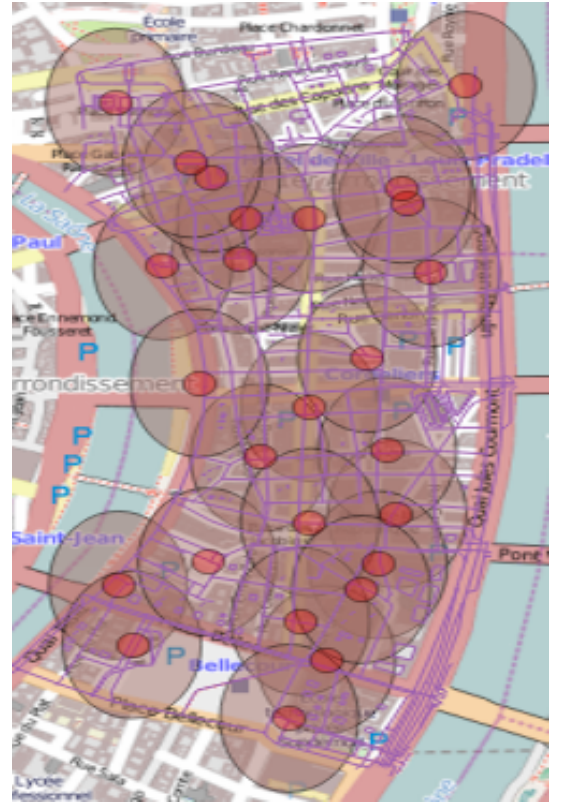

(b) Lyon Presqu'ile area

Fig. 1. Map example. Courtesy GoogleMap and carte.lavilleavelo.org.

absorb the integrity of the traffic of bike $A$. Bike $C$ lies in the overlapped area of base stations 2 and 3 and will share about both. We are aware that practically, when a bike sends data to a given base station, it does not share but we assume that in average the bikes will evenly distribute their traffic among the reachable base stations and both approaches come down to the same in average.

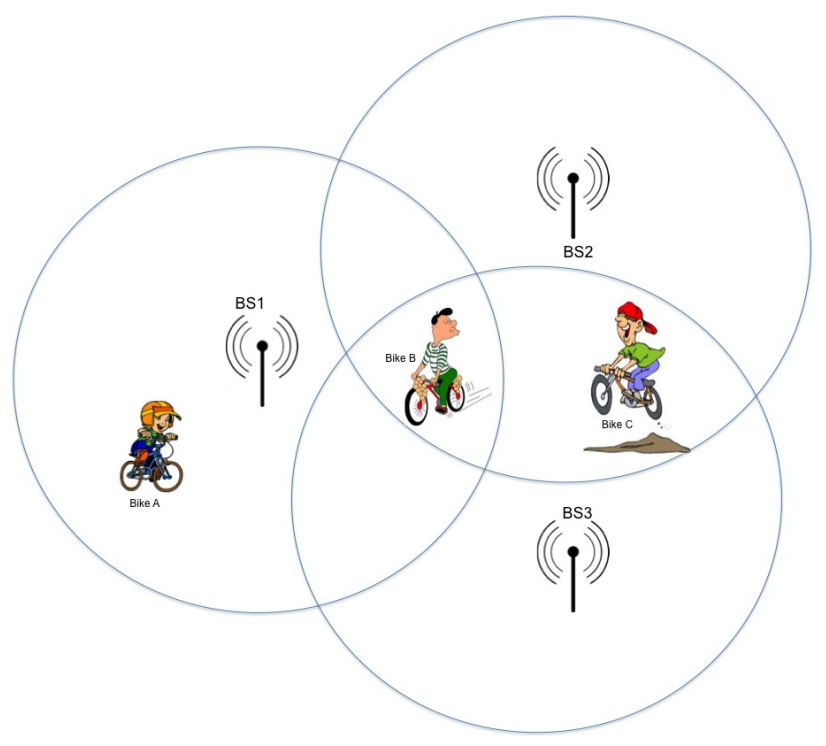

Fig. 2. Illustration of bike coverage.

\section{A. Quantity of data to be offloaded by a bike along a trip}

In this subsection, we are interested in the quantity of data $\chi$ to be offloaded by a bike along a trip. We focus on an individual bike. Note that $\chi$ is independent from the number of other bikes in the area. As we assume that data can be transferred as soon as a bike lies in at least one base station communication range, the quantity of data to be offloaded $\chi$ by a bike along a trip comes down to compute

$$
\chi=\rho \times \tau
$$

where $\tau$ represents the duration a bike lies in at least one base station communication range, the integration over the traveled distance of the number of positions at which the bike lies in a base station range. $\tau$ is thus the integration on a trip of the positions covered by a station such that:

$$
\tau=\frac{1}{v} \times \int_{x}\left(1-P\left(X_{x}=0\right)\right) d x
$$

where $P\left(X_{x}=0\right)$ is the probability that at position $x$, there is no base station (and so $1-P\left(X_{x}=0\right)$ ) is the probability that $x$ is covered by at least one station.

As we assume that base stations are distributed following a stationary Poisson Point Process over the whole area, $P\left(X_{x}=0\right)$ is the probability that there is no node in a surface $\pi R^{2}$ around position $x$ and is the same in every point of the area. So, according to the Slivnyak theorem [15], the number of points under the Palm distribution in such a space follows a discrete Poisson law:

$$
P\left(X_{x}=0\right)=P(X=0)=e^{\left\{-\lambda_{\text {station }} \pi R^{2}\right\}}
$$


Equation 1 thus becomes:

$$
\chi=\frac{\rho}{v} \times \operatorname{dist} \times\left(1-e^{\left\{-\lambda_{\text {station }} \pi R^{2}\right\}}\right)
$$

where dist is the distance traveled by the bike.

\section{B. Quantity of data to be absorbed by a base station}

In this subsection, we are interested in the quantity of data $\mathcal{Q}_{t}$ to be offloaded at time $t$ by a single base station. To do so, we focus on a single base station. As we assume that the traffic generated by a bike located at a position covered by several base stations is, in average, equally distributed/absorbed by each of these base stations, a bike data will be divided by the number of stations in its neighborhood.

Therefore, $\mathcal{Q}_{t}$ can be computed as the expectation of the number of bikes at a single position divided by the number of stations that cover this single position for all position in coverage area of the base station:

$$
\mathcal{Q}_{t}=\rho \int_{S} \Sigma_{i=1}^{\inf } \Sigma_{j=1}^{\inf } \frac{j}{i} P\left(X_{x}=i\right) P\left(Y_{x}^{t}=j\right) d S
$$

Let assume that at a single position $x$, there can be at most one bike at time $t . Y_{x}^{t}$ is thus a random boolean variable that can be equal only to one (with probability $\left.P\left(Y_{n}^{t}=1\right)=\lambda_{\text {bike }}^{t}\right)$ or zero (with probability $P\left(Y_{n}^{t}=0\right)=$ $\left.1-\lambda_{\text {bike }}^{t}\right)$ and is the same for every position $x$ :

$$
\Sigma_{j=1}^{\mathrm{inf}} j P\left(Y_{x}^{t}=j\right)=P\left(Y_{x}^{t}=1\right)=\lambda_{\text {bike }}^{t}
$$

Since we assume uniform Poisson distribution of the bike stations in the space, the expected coverage is the same for every position and each position is independent of the others. According to the Slivnyak theorem [15], as bike stations follow a discrete Poisson law, we have:

$$
\begin{aligned}
P\left(X_{x}=i\right) & =P(X=i) \\
& =\frac{\left(\lambda_{\text {station }} \pi R^{2}\right)^{i}}{i !} e^{\left\{-\lambda_{\text {station }} \pi R^{2}\right\}}
\end{aligned}
$$

and Equation 4 comes down to:

$$
\mathcal{Q}_{t}=\rho \lambda_{\text {bike }}^{t} \times l \times e^{\left\{-\lambda_{\text {station }} \pi R^{2}\right\}} \times \Sigma_{i=1}^{\inf }\left\{\frac{1}{i} \frac{\left(\lambda_{\text {station }} \pi R^{2}\right)^{i}}{i !}\right\}
$$

where $l$ is the length of roads lying in $S$, area covered by the base station.

\section{NumericAl RESUlts}

In this section, we are interested in a first numerical estimation of the study described in Section III. This numerical estimation is of course conditioned by the strong assumptions set in Section II but aims to give the flavor of the evaluated values. We set the transmission ranges of base stations to $R=150 \mathrm{~m}$ (Such a range is displayed on Figure 1(b)) and available throughput such that $\rho=$ $150 \mathrm{Mb} / \mathrm{s}$, which corresponds to a $4 G$ throughput.

\section{A. Distance and time traveled by a bike}

As described in the survey published in [7], in average, a bicycle in a city has an average speed of $15 \mathrm{~km} . \mathrm{h}^{-1}=$ $4,16.10^{-3} \mathrm{~km} \cdot \mathrm{s}^{-1}$ with some global variance in the duration of the trip because of some "set up" incompressible time. According to [7], the bicycle is the quickest transportation mode for travels between 1 and $5 \mathrm{~km}$. The study described in [4] reveals that the average distance traveled by self-service shared renting bikes is between 2 and $3 \mathrm{~km}$, which corresponds to $10 \mathrm{~min}$ trips [7].

Therefore, in our numerical evaluation, we will use dist $=2,5 \mathrm{~km}$.

\section{B. Bike and bike stations densities}

As an example, we take the example of the Lyon area depicted by Figure 1(b) which represents an area of about $1,58 \mathrm{~km}^{2}$ and $85,46 \mathrm{~km}$ of roads and cycleways and counts 26 bike stations and 470 bikes [16]. So at time $t$, we can approximate $\lambda_{\text {station }}$ and $\lambda_{\text {bike }}^{t}$ as:

$$
\lambda_{\text {station }}=\frac{26}{1,58} \simeq 16,45 \text { stations per } \mathrm{km}^{2}
$$

and

$$
\lambda_{\text {bike }}^{t}=\frac{470}{85,46} \simeq 5,50 \text { bikes per km }
$$

\section{Data per bike and coverage}

We replaced the parameters in Equations 3 and 6 by these values. Thus, for the presqu'ile area in Lyon (Figure 1(b)), we obtained that in average, a bike can send up to $\chi=12,490 \mathrm{~Gb}$ along a trip and each bike station needs to be able to absorb a traffic of $\mathcal{Q}_{t}=35514 \mathrm{Mb} . \mathrm{s}^{-1}$.

On the same model, we have extracted the different $\lambda_{\text {bike }}$ and $\lambda_{\text {station }}$ of different districts of the city of Lyon by using the QGIS tool ${ }^{1}$. The different areas of Lyon investigated are shown on Figure 3 and data used for each of these areas are depicted in Table I. By running Equations 3 and 6 on them, we obtained the results gathered in Table II and Figure 4.

\begin{tabular}{|l|c|c|c|c|}
\hline Area \# & $\mathrm{S}\left(\mathrm{km}^{2}\right)$ & $\mathrm{l}(\mathrm{km})$ & $\lambda_{\text {bike }}$ & $\lambda_{\text {station }}$ \\
\hline \hline Lyon 1st arr. & 1,98 & 56,80 & 8,80 & 25 \\
Lyon 2nd arr. & 3,35 & 135,32 & 4,87 & 33 \\
Lyon 3rd arr. & 11,60 & 296,55 & 4,79 & 71 \\
Lyon 4th arr. & 4,40 & 95,38 & 5,45 & 26 \\
Lyon 5th arr. & 3,51 & 95,98 & 3,33 & 16 \\
Lyon 6th arr. & 5,21 & 125,01 & 4,64 & 29 \\
Lyon 7th arr. & 15,50 & 322,92 & 2,60 & 42 \\
Lyon 8th arr. & 12,81 & 259,32 & 2,08 & 27 \\
\hline
\end{tabular}

TABLE I

Data VAlues.

Figure 4(a) shows the quantity of data that a bike could potentially upload during a trip. This gives a higher bound since it considers the better capacity. Results show that this quantity clearly depends of the area in which the bike

\footnotetext{
${ }^{1}$ http://qgis.org/en/site/index.html
} 


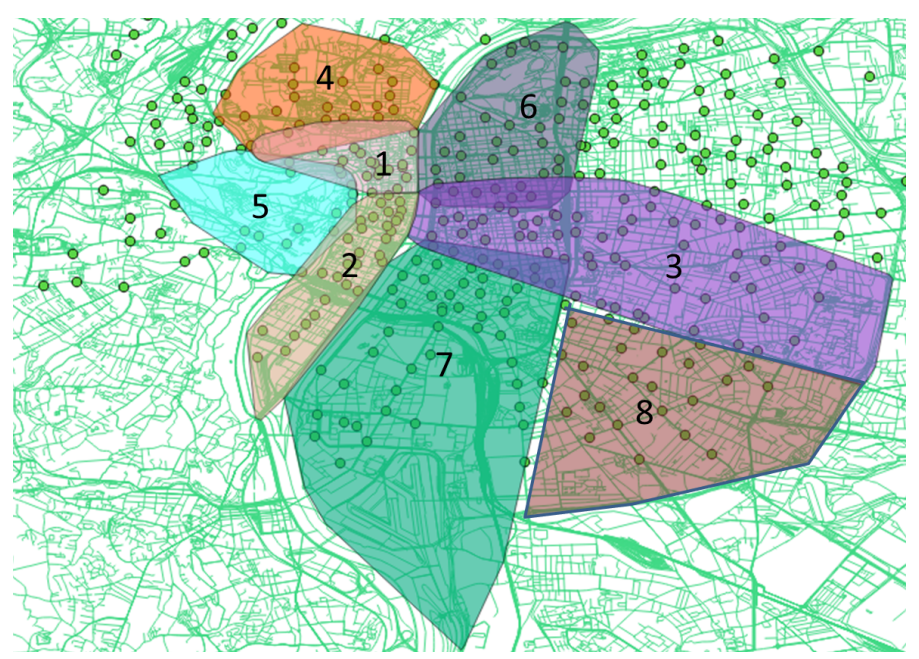

Fig. 3. Different areas of Lyon under study.

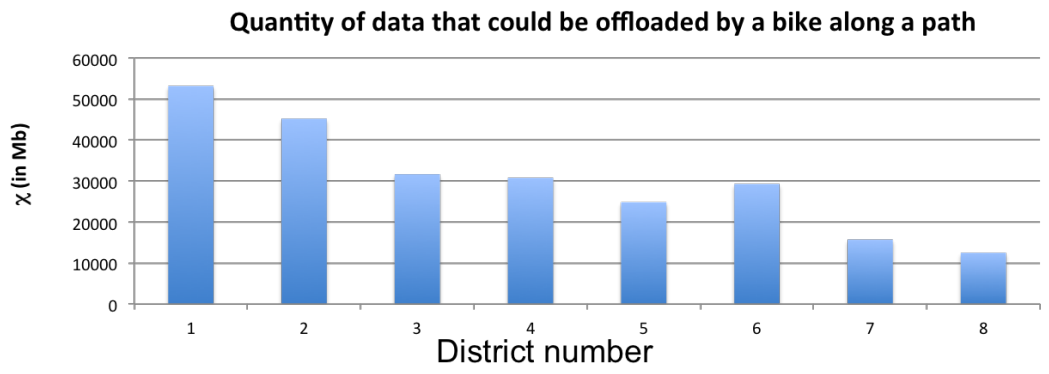

(a) $\chi$

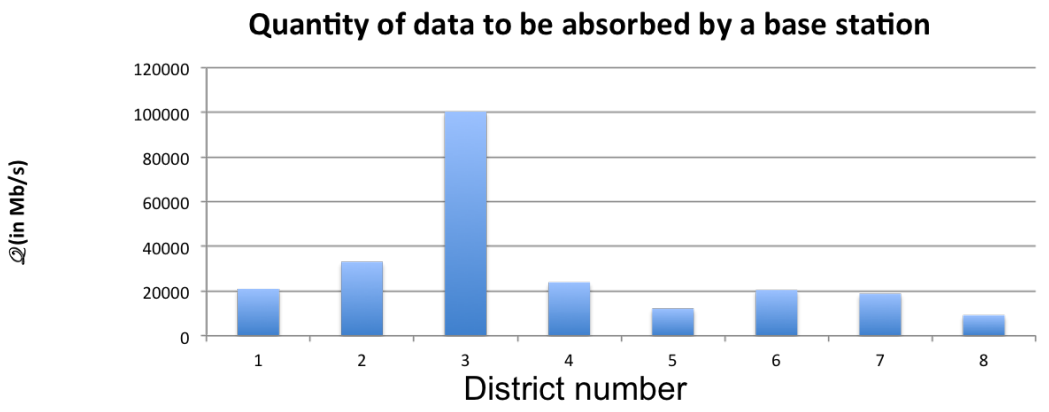

(b) $\mathcal{Q}_{t}$

Fig. 4. Results per district area.

travels and on the bike station distributions. Obviously, the denser bike stations distribution, the more stations encountered on a path and the higher possibilities to upload data.

Figure 4(b) shows the quantity of data a station should be able to absorb from the bikes. Again we can observe a disparity between the different areas. These values depend of the density of bikes and of the density of bike stations in the area. Bike stations are generally distributed based on the human activity. So, we observe that some touristic and working areas (like areas 1 and 2) that counts a high bike density have also a higher density of stations and

\begin{tabular}{|l|c|c|}
\hline Area \# & $\chi(\mathrm{Mb})$ & $\mathcal{Q}_{t}\left({\mathrm{Mb} . \mathrm{s}^{-1}}^{-1}\right)$ \\
\hline \hline Lyon 1st arr. & 14,75 & 20988 \\
Lyon 2nd arr. & 12,54 & 33119 \\
Lyon 3rd arr. & 8,78 & 100388 \\
Lyon 4th arr. & 8,54 & 23924 \\
Lyon 5th arr. & 6,89 & 12180 \\
Lyon 6th arr. & 8,14 & 20475 \\
Lyon 7th arr. & 4,36 & 18833 \\
Lyon 8th arr. & 3,46 & 9187 \\
\hline
\end{tabular}

TABLE II

REsults. 
so the traffic to be absorbed is well relatively low and equivalent to the one in residential areas (like district 8) which have less bike stations and less bikes. But there are also some mix area like the $3^{\text {rd }}$ district that counts few bike stations located around offices and train stations but with a large number of bikes. Such results are confirmed by data depicted in Table III that shows the proportion of road/bicycle path/etc covered in an area (with $R=$ $150 \mathrm{~m}$ ). This shows in such cases the necessity to have some more powerful base stations (either in terms of coverage or capacity) in these areas or to deploy additional base stations to alleviate the data traffic on other stations.

\begin{tabular}{|l|c|c|c|}
\hline Area \# & $\mathrm{l}(\mathrm{km})$ & covered path length $(\mathrm{km})$ & ratio \\
\hline \hline Lyon 1st arr. & 56,80 & 25,12 & 44,23 \\
Lyon 2nd arr. & 135,32 & 71,85 & 53,10 \\
Lyon 3rd arr. & 296,55 & 121,45 & 40,95 \\
Lyon 4th arr. & 95,38 & 51,56 & 54,06 \\
Lyon 5th arr. & 95,98 & 39,87 & 41,54 \\
Lyon 6th arr. & 125,01 & 73,93 & 59,14 \\
Lyon 7th arr. & 322,92 & 213 & 65,96 \\
Lyon 8th arr. & 259,32 & 104,11 & 40,15 \\
\hline
\end{tabular}

TABLE III

Approximative coverage With a radius $R=150 \mathrm{~m}$.

\section{Discussion}

Based on the kind of sensors to be deployed on bikes, this study may lay the basis for different research areas. Indeed, if sensors are to weak in terms of memory capacity or that there is a real need to send data in real time, the results depicted by Figure 4(b) show there are some areas with huge quantity of data to absorb. In addition, as depicted by Table III, with a range of $R=150 \mathrm{~m}$, the percentage of roads covered by a base station is about $50 \%$ only. Other mechanisms should thus be triggered. For instance, if the bike can not wait to offload its data and that it lays in an area which is not covered by any base station, it may consider to trigger a multi-hop routing by sending its own data to one or several other bikes that will carry them for it. The current study could thus give some insight to the necessity of such a mechanism and if needed, provide the bike with some clues on when activating it and on to whom send the data. By the same token, the current study could show the need to deploy additional base stations and help in the localisation of them and on the tuning of the transmission range.

As already claimed, this paper only presents the basis study for such a deployment. Parameters and models have been simplified but it is worth noticing that each of them can be easily replaced in the model by more complex models. We intend for instance to include more realistic bike distribution models based on inputs that our City partners (Lyon, Lille, Istanbul and London) and bike operators partners (BTwin, JCDecaux, Transpole) will provide to us. Indeed, in some areas with less bike stations, the density of bikes may be lower since the areas to travel are larger, which reduces the need of additional base stations. These values also have to be weighted as a function of the time of the day and the weather that greatly influences the bike utilization.

\section{CONClusion}

In this paper, we presented a framework on which city bikes are equipped with different sensors to help in many applications ranging from road improvements going through medical concerns. We have laid the basis of a theoretical study to dimension the network infrastructure and adapt the network protocols. As a future work, we intend to make our model more complex by introducing more accurate models for bike and bike stations distribution provided by our different partners. We also plan to realize some in situ experimentations to improve and feed our framework.

\section{ACKNOWLEDGEMENT}

This work has been realized in the framework of the IPL CityLab@Inria. It has been partially supported by a grant from the CPER Nord Pas de Calais CIA and the FP7 VITAL project.

\section{REFERENCES}

[1] Smart bike. http://www.macg.co/video/2014/07/un-velo-quise-connecte-au-smartphone-83498, 2014.

[2] Urban sustainability and the simple bicycle. http://thisbigcity.net/urban-sustainability-and-the-simplebicycle/, 2014.

[3] études et qualité Ademe. Usage du vélo en location. quelles pratiques, quelles motivations ? Technical report, Ademe, 2009. www2.ademe.fr/servlet/getBin?name.pdf.

[4] Altermodal. Les services vélo, des outils efficaces de changement modal. Technical report, Ademe, 2009. http://www.fubicy.org/IMG/pdf/velostation04resume.pdf.

[5] Atout. Le marché du vélo. Technical report, Chambre des métiers et de l'artisanat, 2013. http://www.cma74.fr/IMG/pdf/CRMA_ATOUTS_etude_velo_201307.pdf.

[6] Urban Transportation Caucus. Urban transportation report card. Technical report, transportation alternatives, 2007. https://www.transalt.org/files/news/reports/Urban_Transpo_Report_Car

[7] citycle. http://www.citycle.com/427-temps-de-deplacement-enville.

[8] Groupement des Autorités Responsables du Transport. Tour de france des services vélos. Technical report, Gart, 2009. www.gart.org/content/download/14871/145973/file/Cliquezici.pdf.

[9] S. B. Eisenman, E. Miluzzo, N. D. Lane, R. A. Peterson, G s. Ahn, and A. T. Campbell. The bikenet mobile sensing system for cyclist experience mapping. In In Proc. of 5th ACM Conf. on Embedded Networked Sensor Systems (Sensys), pages 6-9, 2007.

[10] Canada government. Urban bicycle planning. Urban Transportation Showcase Program, 2012.

[11] M. Naphade, G. Banavar, C. Harrison, J. Paraszczak, and R. Morris. Smarter cities and their innovation challenges. Computer, 44(6), 2011.

[12] The European network for cycling expertise. cycling and transport. Technical report, velo.info, 2014 http://www.velo.info/Library/Cycling_Transport.pdf.

[13] Niches. Public bicycles. Technical report, Niches, 2006. edoc.difu.de/edoc.php?id=J1EOT82V.

[14] Adele Peters. http://www.fastcoexist.com/3034313/a-new-apptracks-where-cyclists-actually-ride-to-help-plan-better-paths.

[15] D. Stoyan, S. Kendall, and J. Mecke. Stochastic geometry and its applications, second edition. John Wiley \& Sons, 1995.

[16] Velo V. http://www.velov.grandlyon.com/. 